\title{
ANALISIS INDEKS VEGETASI MANGROVE MENGGUNAKAN CITRA SATELIT ALOS AVNIR-2 (Studi Kasus: Estuari Perancak, Bali)
}

\author{
ANALYSIS OF MANGROVE VEGETATION INDEX USING AN ALOS AVNIR-2 SATELLITE \\ (A case study: Estuari Perancak, Bali)
}

\author{
Anak Agung Sagung Ratih Prameswari ${ }^{1}$, Teguh Hariyanto ${ }^{1}$, Frida Sidik ${ }^{2}$ \\ ${ }^{1}$ Jurusan Teknik Geomatika FTSP-ITS, Kampus ITS Sukolilo, Surabaya, 60111 \\ ${ }^{2}$ Balai Penelitian dan Observasi Laut, Balitbang Kelautan dan Perikanan, Kementerian Kelautan dan Perikanan, Bali \\ Email: teguh_hr@geodesy.its.ac.id
}

\begin{abstract}
Abstrak
Hutan mangrove di kawasan Estuari Perancak, Jembrana awalnya memiliki area yang sangat luas. Namun seiring dengan perkembangan penduduk, dan peningkatan kebutuhan masyarakat, mulailah pengubahan lahan hutan mangrove menjadi tambak yang mengambil hampir lebih dari 50\% lahan asli mangrove. Dengan perkembangan zaman, terdapat teknologi penginderaan jauh yang dapat mengawasi persebaran mangrove alami dan yang ditanami menggunakan indeks vegetasi. Indeks vegetasi yang dapat digunakan antara lain NDVI, EVI2, dan SAVI. Dalam penelitian ini, indeks vegetasi tersebut dimasukkan dalam citra satelit ALOS AVNIR-2 untuk mengetahui rentan nilai indeks vegetasi mangrove alami dan yang ditanami di Estuari Perancak, Jembrana-Bali.

Lokasi penelitian penelitian ini berada di Estuari Perancak, Jembrana, tepatnya di desa Budeng dan desa Perancak. Estuari Perancak secara geografis terletak antara $8^{\circ} 22^{\prime} 30^{\prime \prime}$ LS sampai $8^{\circ} 24^{\prime} 18^{\prime \prime}$ LS dan $114^{\circ} 36^{\prime} 18^{\prime \prime}$ BT sampai $114^{\circ}$ $38^{\prime} 31,2^{\prime \prime}$ BT. Metode analisa indeks vegetasi yang digunakan pada penelitian ini adalah NDVI (Normalized Difference Vegetation Index), EVI2 (Enhanced Vegetation Index-2), dan SAVI (Soil Adjusted Vegetation Index).

Hasil penelitian ini menunjukkan bahwa citra ALOS AVNIR-2 mampu digunakan dalam menghasilkan data indeks vegetasi dengan algoritma NDVI, EVI2, dan SAVI. Indeks Vegetasi EVI2 menghasilkan keakurasian hubungan yang lebih baik dibandingkan metode NDVI dan SAVI dimana koefisien determinasinya adalah 0,001 . Sedangkan yang memiliki keakurasian hubungan yang lebih baik terhadap EVI2 adalah SAVI, dimana koefisien determinannya sebesar 0,987. Total luas area mangrove di Estuari Perancak adalah 114,19 Ha, dengan pembagian mangrove alami seluas 69,04 Ha dan mangrove ditanami seluas 45,15 $\mathrm{Ha}$.
\end{abstract}

Kata Kunci: Indeks Vegetasi, Mangrove, ALOS AVNIR-2

\begin{abstract}
Mangroves in Estuary Perancak, Jembrana initially have a very wide area. But along with the population, and the increasing needs of the community, begin the conversion of mangrove forests into farms that took almost more than $50 \%$ of the original mangrove land. With the times, there is a remote sensing technology that can monitor the distribution of natural and planted mangrove using vegetation index. Vegetation index that can be used, among others, NDVI, EVI2, and SAVI. In this study, the vegetation index included in the satellite image AVNIR ALOS-2 to determine vulnerable mangrove vegetation index value of natural and planted in Estuary Perancak, Jembrana, Bali.

This research location is in the Estuary Perancak, Jembrana, precisely in the village of Budeng and Perancak. Estuary Perancak is geographically located between $8022^{\prime} 30^{\prime \prime}$ LS to $8024^{\prime} 18^{\prime \prime} L S$ and $114036^{\prime} 18^{\prime \prime}$ BT to $114038^{\prime \prime} 31,2^{\prime \prime}$ BT. Vegetation index analysis method used in this study is the NDVI (Normalized Difference Vegetation Index), EVI2 (Enhanced Vegetation Index - 2), and SAVI (Soil Adjusted Vegetation Index).

These results indicate that AVNIR ALOS-2 can be used to generate the data of vegetation index with NDVI, EVI2, and SAVI algorithm. Vegetation Index EVI2 produce accuracy better relationship than NDVI and SAVI method wherein the determination coefficient was 0.001 . While that has accuracy better relationship towards EVI2 is SAVI, where the coefficient determinant of 0.987. The total area of mangroves in Estuarine Perancak is 114,19 hectares, with the distribution of natural mangrove area of 69,04 hectares and planted mangrove area of 45,15 hectares.
\end{abstract}




\section{PENDAHULUAN}

\section{Latar Belakang}

Berdasarkan UU no. 41 Tahun 1999 tentang Kehutanan bahwa mangrove merupakan ekosistem hutan, dan oleh karena itu, maka pemerintah bertanggung jawab dalam pengelolaan yang berasaskan manfaat dan lestari, kerakyatan, keadilan, kebersamaan, keterbukaan dan keterpaduan. Selanjutnya dalam kaitan kondisi mangrove yang rusak, kepada setiap orang yang memiliki, pengelola dan atau memanfaatkan hutan kritis atau produksi, wajib melaksanakan rehabilitasi hutan untuk tujuan perlindungan konservasi. UndangUndang tersebut dibuat oleh pemerintah dalam rangka menjaga kelestarian hutan mangrove di Indonesia. Namun seiring dengan pertumbuhan penduduk yang semakin meningkat, mengakibatkan peningkatan pembangunan infrastruktur umum di sekitar wilayah pesisir.

Hutan mangrove di Bali tersebar di beberapa lokasi dengan luas sekitar $3.067,71$ ha. Hutan mangrove terbesar terdapat pada tiga lokasi, yaitu Tahura atau Taman Hutan Raya Ngurah Rai dengan luas $1.373,5$ ha, Nusa Lembongan dengan luas 202 ha, dan lokasi ketiga terletak di Taman Nasional Bali Barat dengan luas 602 ha. Hutan mangrove di kawasan Estuari Perancak dengan luas 177,09 ha merupakan sisa luas hutan setelah di konversi menjadi areal pertambakan sekitar tahun 1980 (Balai Riset dan Observasi Kelautan, 2004). Lebih dari 390 ha merupakan lahan tambak, baik yang masih produktif maupun yang sudah tidak produktif, serta 178,6 ha merupakan ekosistem mangrove (BROK, 2009).

Penggunaan data satelit penginderaan jauh telah banyak digunakan untuk pemantauan keadaan vegetasi di bumi. Salah satu teknologi penginderaan jauh tersebut adalah satelit ALOS AVNIR-2. Citra ini memiliki resolusi spasial $10 \mathrm{~m}$ dan resolusi spectral sebanyak 4 band. Indeks vegetasi merupakan algoritma yang diterapkan dalam citra satelit untuk menonjolkan aspek vegetasi. Metode analisa indeks vegetasi ada beberapa macam antara lain NDVI (Normalized Difference Vegetation Index), EVI-2 (Enhanced Vegetation Index-2), dan SAVI (Soil Adjusted Vegetation Index).

\section{Perumusan Masalah}

Rumusan masalah dalam penelitian ini adalah bagaimana hasil analisa perbandingan nilai indeks vegetasi untuk mangrove alami dan yang ditanami menggunakan citra satelit ALOS-AVNIR2.

\section{Batasan Masalah}

Adapun batasan permasalahan dari penelitian ini adalah:

a. Wilayah studi yang digunakan dalam penelitian ini adalah wilayah Estuari Perancak, Bali

b. Data primer yang digunakan adalah citra satelit ALOS AVNIR-2 tahun 2011

c. Metode analisa indeks vegetasi yang digunakan adalah NDVI, EVI, dan SAVI

\section{Tujuan}

Adapun tujuan penelitian ini adalah memberikan informasi tentang:

a. Mengetahui kemampuan citra ALOS AVNIR-2 dalam mendeteksi vegetasi

b. Membandingkan algoritma untuk vegetasi mangrove

c. Menguji hasil algoritma dengan data lapangan

\section{Manfaat}

Manfaat dari penelitian ini adalah untuk menganalisa pola hidup mangrove untuk menjaga ekosistem pesisir pantai agar wilayah daratannya tidak semakin berkurang.

\section{METODOLOGI PENELITIAN}

\section{Data Dan Peralatan}

- Data

Data yang digunakan dalam penelitian ini adalah:

1. Data Citra Satelit ALOS AVNIR-2 Tahun 2011

2. Data Peta RBI 1:25.000 kawasan Estuari Perancak

3. Data insitu pengklasifikasian mangrove alami dan ditanami

4. Koordinat sample dari lapangan untuk uji ketelitian klasifikasi citra 


\section{- Peralatan}

Peralatan yang digunakan dalam penelitian ini adalah:

1. GPS handheld untuk pengambilan koordinat lapangan

2. Meteran

3. Perangkat lunak pengolahan citra

4. ArcGIS

5. Microsoft Office 2007

\section{Metode Penelitian}

Lokasi penelitian ini berada di Estuari Perancak, tepatnya di desa Budeng dan desa Perancak, Kabupaten Jembrana, Provinsi Bali. Estuari Perancak secara geografis terletak antara 80 22' 30" LS sampai 8o 24'18" LS dan $114036^{\prime} 18^{\prime \prime}$ BT sampai 1140 o $38^{\prime} 31,2^{\prime \prime}$ BT.

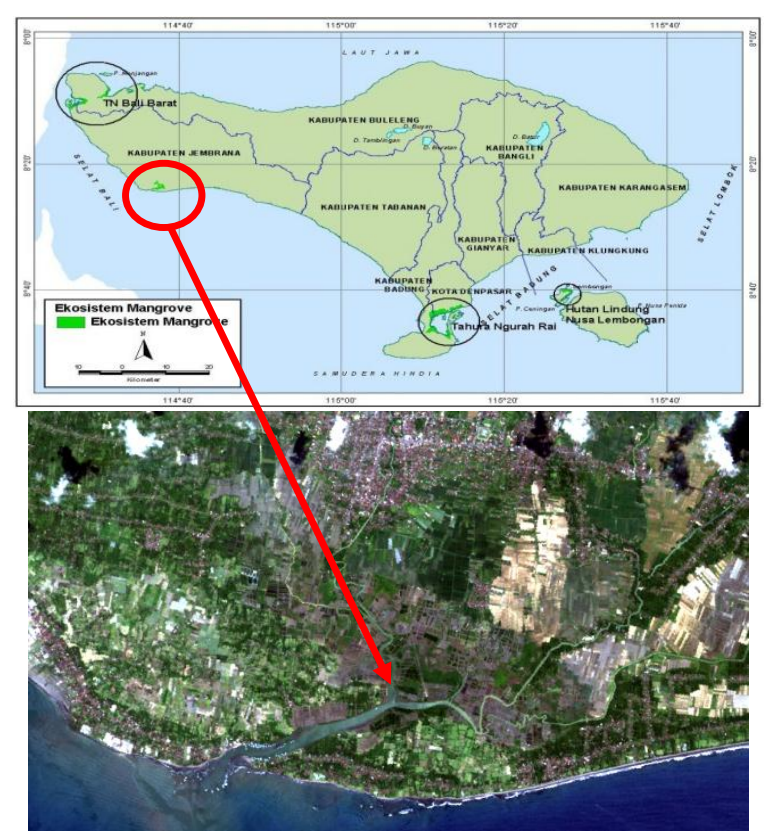

Gambar 1. Lokasi Penelitian

Sumber: Dinas Kehutanan Bali, 2010 (atas) dan Citra ALOS AVNIR-2 (bawah)

Adapun metodologi yang digunakan dalam penelitian secara keseluruhan ini ialah sebagai berikut:

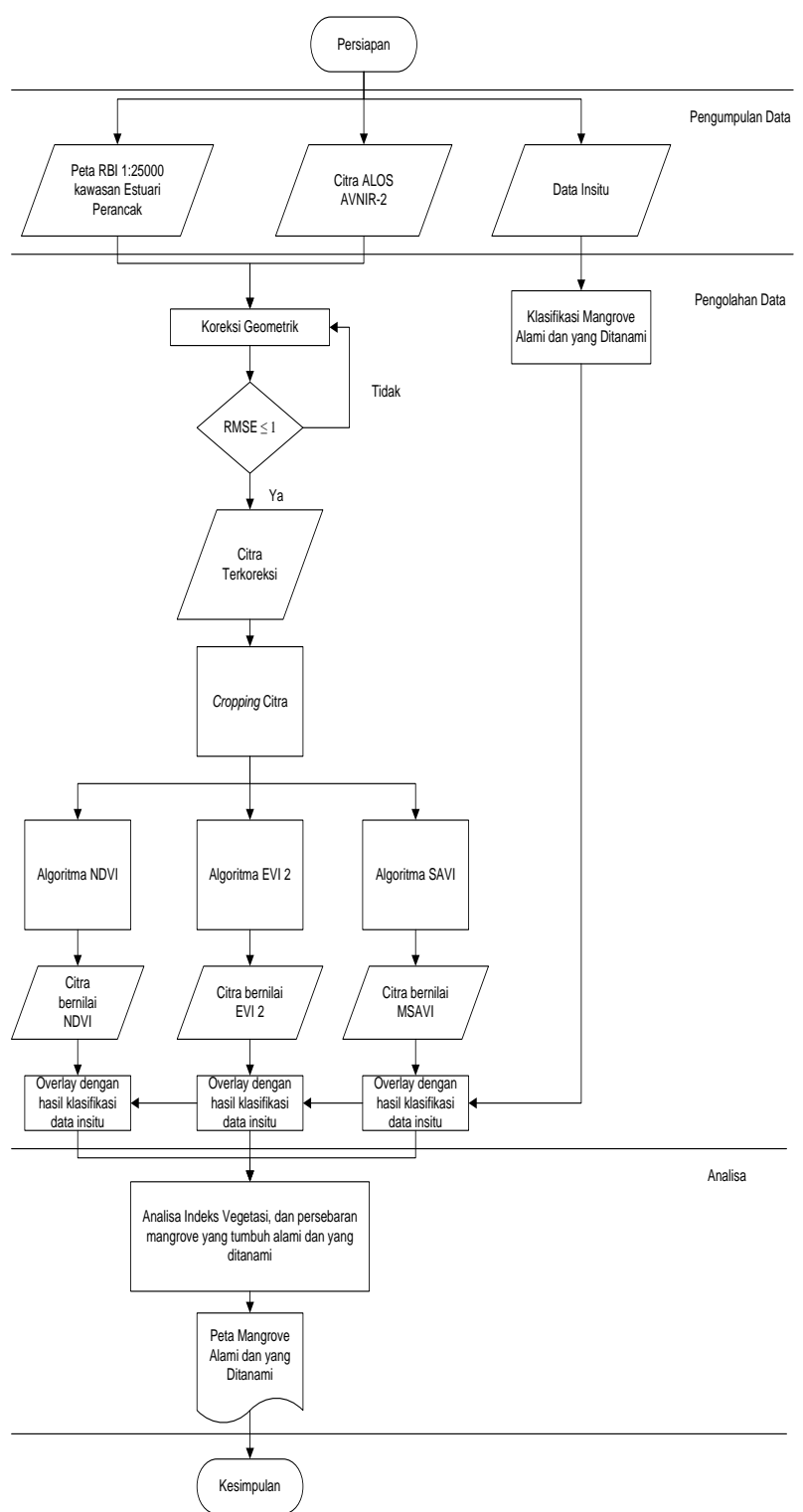

Gambar 2. Diagram Alir Pengumpulan, Pengolahan, dan Analisa Data

Adapun penjelasan diagram alir tahapan pengolahan data sebagai berikut:

1. Koreksi Geometrik

Proses koreksi geometrik dilakukan pada kedua citra untuk mendapatkan sistem koordinat dan proyeksi yang sama. Proses yang dilakukan adalah proses rektifikasi yang merupakan koreksi geometric antara citra dengan peta RBI. Koreksi geometrik yang bersifat random diselesaikan dengan analisa titik kontrol tanah (ground control point) melalui fungsi transformasi yang menghubungkan antara sistem koordinat tanah dan citra. Menggunakan perhitungan RMS (Root Mean Square), dengan ketentuan 
RMS harus kurang dari 1 (RMSE $\leq 1$ ). Apabila RMS masih lebih besar dari 1, maka perlu dilakukan koreksi geometrik lagi.

Sistem proyeksi yang digunakan adalah Universal Transverse Mercator zone 50S dan datum yang digunakan adalah WGS 1984. Hasil koreksi geometrik pada citra ALOS AVNIR-2 sebesar 1.881 piksel untuk total RMSerror dan untuk rata-rata RMSerror sebesar 0.235

2. Cropping Citra

Pada tahapan ini dilakukan pemotongan citra yang sesuai dengan lokasi penelitian dan tujuan interpretasi. Pemotongan dikalukan dengan software opensource

3. Klasifikasi Terbimbing

Lakukan klasifikasi terbimbing dengan menggambarkan training area untuk mangrove alami dan yang ditanami yang harus dipisahkan pada klasifikasi dan menggunakan karakteristik spectral masingmasing area untuk klasifikasi citra.

4. Algoritma Indeks Vegetasi

Pada tahap ini dilakukan pemberian algoritma indeks vegetasi pada citra ALOS AVNIR-2 yang telah dipotong. Pemberian algoritma dapat dilakukan di software opensource. Karena dalam penelitian ini menggunakan 3 algoritma indeks vegetasi, maka proses yang dilakukan sebanyak tiga kali dengan algoritma yang berbeda.

Penelitian ini menggunakan 3 Indeks vegetasi yaitu NDVI (Normalized Difference Vegetation Index), EVI2 (Enhanced Vegetation Index - 2), dan SAVI (Soil Adjusted Vegetation Index). Berikut adalah algoritma ketiga indeks vegetasi tersebut:

$N D V I=\frac{N I R-R E D}{N I R+R E D}$

$E V I 2=G \frac{\rho_{\text {NIR }}-\rho_{\text {Red }}}{\rho_{\text {NIR }}+2,4 \times \rho_{\text {Red }}+1}$

$S A V I=\frac{(1+L)(N I R-R E D)}{N I R+R E D+L}$

Dimana:

NIR : nilai reflektan band spektral infra merah dekat

RED : nilai reflektan band spektral merah

$$
\begin{aligned}
& G: \text { gain factor }=2,5 \\
& L: \text { factor kalibrasi tanah }=0,5
\end{aligned}
$$

\section{HASIL DAN PEMBAHASAN}

Hasil dari pemberian algoritma indeks vegetasi menunjukkan hasil yaitu -1 sampai 1 . Hasil nilai ketiga indeks vegetasi tersebut adalah sebagai berikut.

Tabel 1. Hasil Algoritma Indeks Vegetasi

\begin{tabular}{llll}
\hline $\begin{array}{l}\text { Indeks } \\
\text { Vegetasi }\end{array}$ & $\begin{array}{l}\text { Nilai } \\
\text { Minimum }\end{array}$ & $\begin{array}{l}\text { Nilai } \\
\text { Maksimum }\end{array}$ & $\begin{array}{l}\text { Standart } \\
\text { Deviasi }\end{array}$ \\
\hline NDVI & -0.723 & 0.530 & 0.127 \\
\hline EVI2 & -0.815 & 0.992 & 0.179 \\
\hline SAVI & -1.079 & 0.792 & 0.190 \\
\hline
\end{tabular}

A. Analisa Indeks Vegetasi

Berikut merupakan hasil algoritma NDVI, EVI2, dan SAVI yang telah dicocokkan dengan sampel di lapangan.

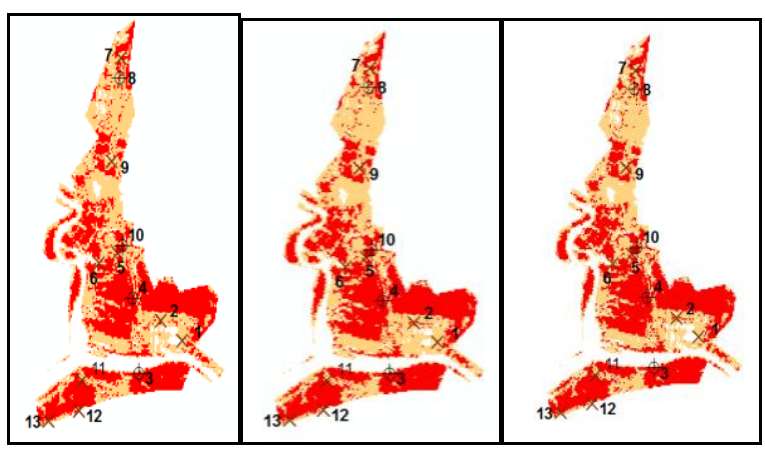

Gambar 3. Hasil Algoritma Indeks Vegetasi NDVI, EVI2, dan SAVI

Dari ketiga perbandingan hubungan diatas, dapat disimpulkan bahwa algoritma yang memiliki hubungan paling besar dengan parameter kerapatan pohon mangrove per area adalah algoritma NDVI dengan nilai koefisien determinan sebesar 0,126. Sedangkan nilai koefisien determinan EVI2 dan SAVI sebesar 0,109 . 


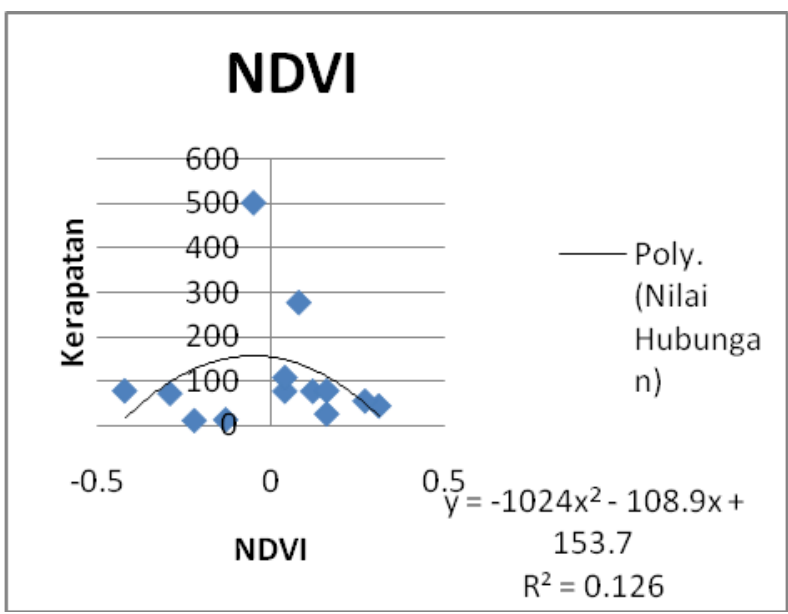

Gambar 4. Grafik Hubungan NDVI dengan Kerapatan

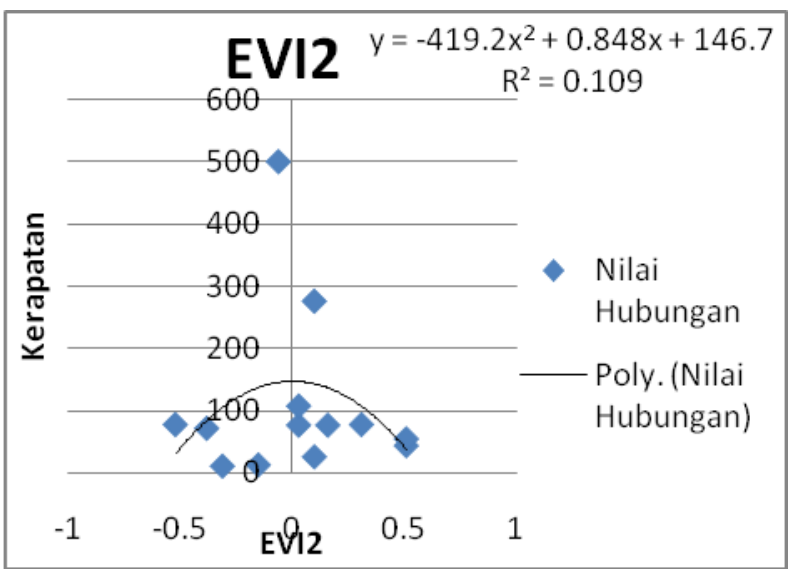

Gambar 5. Grafik Hubungan EVI2 dengan Kerapatan

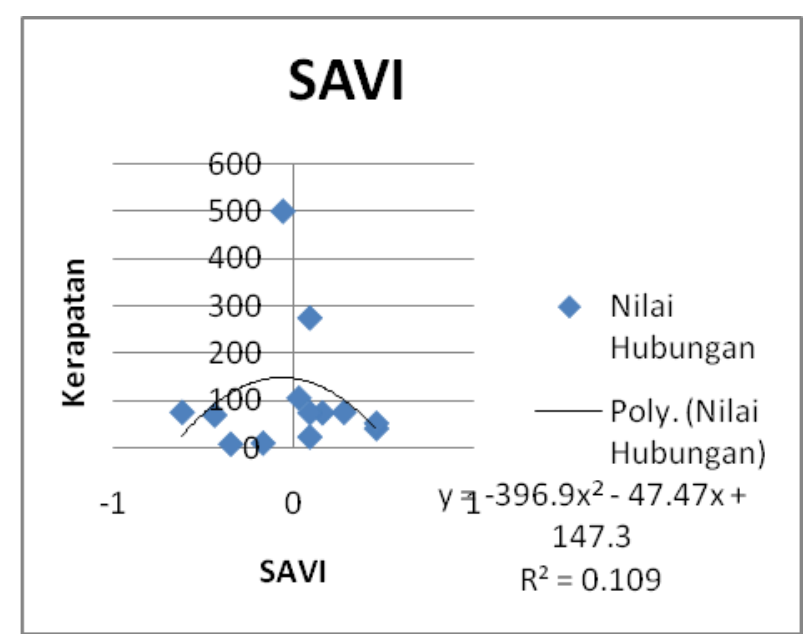

Gambar 6. Grafik Hubungan SAVI dengan Kerapatan

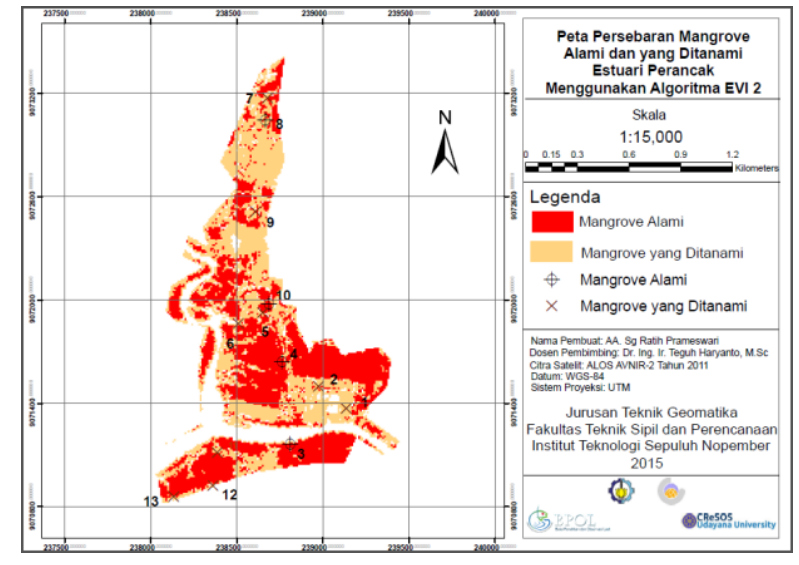

Gambar 7. Peta Persebaran Mangrove Alami dan yang Ditanami Estuari perancak

\section{PENUTUP}

Citra ALOS AVNIR-2 dapat digunakan dalam mendeteksi area vegetasi mangrove menggunakan algoritma indeks vegetasi NDVI, EVI-2, dan SAVI

Nilai hubungan antara algoritma indeks vegetasi dengan nilai kerapatan pohon mangrove per area diketahui sangat kecil, yaitu algoritma NDVI dengan nilai koefisien determinan sebesar 0,126. Sedangkan nilai koefisien determinan EVI2 dan SAVI sebesar 0,109.

Melihat hasil nilai hubungan indeks vegetasi dengan kerapatan pohon mangrove yang sangat kecil, hal ini kemungkinan disebabkan karena data citra ALOS AVNIR-2 tahun 2011 dan data insitu tahun 2015 maka disarankan agar jarak waktu pengambilan data citra dan data insitu tidak terlalu jauh.

Kendala dalam proses pengerjaan penelitian ini adalah sulitnya membedakan vegetasi mangrove dengan vegetasi lainnya dikarenakan wilayah kajian yang kecil, maka dari itu diperlukan citra dengna resolusi tinggi untuk hasi yang lebih maksimal.

\section{UCAPAN TERIMAKASIH}

Penulis A.R.P mengucapkan terima kasih kepada Balai Penelitian dan Observasi Laut selaku instansi pembimbing dan pengambilan dan lapangan, serta Center of Remote Sensing and Ocean Science (CReSOS) yang telah memberikan data citra satelit guna mendukung dalam keberhasilan penelitian ini. 


\section{DAFTAR PUSTAKA}

Budiyanto, E. 2012. “Indeks Vegetasi”. http://geo.fis. unesa.ac.id/web/index.php/en/penginderaan -jauh77-indeks-vegetasi (4 Nov. 2014)

Elachi, C. and Zyl, J. J, 2006. Introduction To The Physics and Techniques of Remote Sensing. New Jersey: John Wiley \& Sons Inc.

James, K.M, 2010. Remote Sensing. Jakarta: Gramedia. JAXA, 2008. ALOS Data User Handbook Revision C. Japan: Japan Aerospace Exploration Agency.

Kusmana, C, 2009. Pengelolaan Sistem Mangrove Secara Terpadu. Workshop Pengelolaan Ekosistem Mangrove di Jawa Barat. Jatinangor.

Kustandyo, H, 2013. Studi Tingkat Kerapatan Mangrove Menggunakan Indeks Vegetasi Dari Citra Multispektral. Surabaya.

Landgrebe, D, 2003. Signal Theory Methods In Multispectral Remote Sensing. New Jersey: John Willey \& Sons Inc.

Lillesand and Kiefer, 1998. Penginderaan Jauh dan Interpretasi Citra Penginderaan Jauh. Yogyakarta: Gadjahmada University Press.

Prasali, I., and A.S, K, 2004. Pengkajian Nilai Indeks Vegetasi Data Modis dengan Menerapkan Beberapa Algoritma Pengolahan Data Indeks Vegetasi. Jurnal Penginderaan Jauh dan Pengolahan Data Citra Digital Vol 1 No 1.

Saefurahman, G, 2008. Distribusi, Kerapatan dan Perubahan Luas Vegetasi Mangrove Gugus Pulau Pari Kepulauan Seribu Menggunakan Citra FORMOSAT-2 dan LANDSAT 7/ETM+. Program Studi IImu dan Teknologi Kelautan Bogor. 